\title{
A novel progesterone receptor membrane component (PGRMC) in the human and swine parasite Taenia solium: implications to the host-parasite relationship
}

Hugo Aguilar-Díaz , Karen E. Nava-Castro², Galileo Escobedo ${ }^{3}$, Lenin Domínguez-Ramírez ${ }^{4}$ Martín García-Varela ${ }^{5}$, Víctor H. del Río-Araiza ${ }^{6}$, Margarita I. Palacios-Arreola ${ }^{6}$ and Jorge Morales-Montor ${ }^{6 *}$ (D)

\begin{abstract}
Background: We have previously reported that progesterone $\left(\mathrm{P}_{4}\right)$ has a direct in vitro effect on the scolex evagination and growth of Taenia solium cysticerci. Here, we explored the hypothesis that the $\mathrm{P}_{4}$ direct effect on T. solium might be mediated by a novel steroid-binding parasite protein.

Methods: By way of using immunofluorescent confocal microscopy, flow cytometry analysis, doubledimension electrophoresis analysis, and sequencing the corresponding protein spot, we detected a novel PGRMC in T. solium. Molecular modeling studies accompanied by computer docking using the sequenced protein, together with phylogenetic analysis and sequence alignment clearly demonstrated that $T$. solium PGRMC is from parasite origin.

Results: Our results show that $\mathrm{P}_{4}$ in vitro increases parasite evagination and scolex size. Using immunofluorescent confocal microscopy, we detected that parasite cells showed expression of a $\mathrm{P}_{4}$-binding like protein exclusively located at the cysticercus subtegumental tissue. Presence of the $\mathrm{P}_{4}$-binding protein in cyst cells was also confirmed by flow cytometry. Double-dimension electrophoresis analysis, followed by sequencing the corresponding protein spot, revealed a protein that was previously reported in the T. solium genome belonging to a membrane-associated progesterone receptor component (PGRMC). Molecular modeling studies accompanied by computer docking using the sequenced protein showed that PGRMC is potentially able to bind steroid hormones such as progesterone, estradiol, testosterone and dihydrodrotestosterone with different affinities. Phylogenetic analysis and sequence alignment clearly demonstrated that T. solium PGRMC is related to a steroid-binding protein of Echinoccocus granulosus, both of them being nested within a cluster including similar proteins present in platyhelminths such as Schistocephalus solidus and Schistosoma haematobium.
\end{abstract}

Conclusion: Progesterone may directly act upon T. solium cysticerci probably by binding to PGRMC. This research has implications in the field of host-parasite co-evolution as well as the sex-associated susceptibility to this infection. In a more practical matter, present results may contribute to the molecular design of new drugs with anti-parasite actions.

Keywords: Taenia solium, Cysticerci, Parasite, Helminth, PGRMC, Hormone receptors, Progesterone

\footnotetext{
*Correspondence: jmontor66@biomedicas.unam.mx;

jmontor66@hotmail.com

${ }^{6}$ Departamento de Inmunología, Instituto de Investigaciones Biomédicas, Universidad Nacional Autónoma de México, AP 70228, 04510 Ciudad de Mexico, DF, Mexico

Full list of author information is available at the end of the article
} 


\section{Background}

Human neurocysticercosis and porcine cysticercosis are caused by the metacestode stage of the cestode parasite Taenia solium. Neurocysticercosis is still a serious human health problem, whereas porcine cysticercosisis is a veterinary problem in many developing countries and mainly in underdeveloped countries. Neurocysticercosis approximately affects 50 million people worldwide [1-4]. Human neurocysticercosis is considered as an emergent disease in the USA [4]. Swine cysticercosis leads to major economic losses and also promotes continuity of the infectious cycle in humans $[5,6]$.

One of the most important aspects during $T$. solium infection is the evagination process of $T$. solium cysticerci that takes place in the human gut. Evagination is the key step that will release the adult worm, which can produce thousands of eggs. Infective eggs released with human stools can contaminate the environment and infect pigs, where the eggs rapidly differentiate into cysticerci. Cysticerci are mainly located in the skeletal muscles in pigs or brain tissue in humans, where the most severe symptoms are observed in patients with neurocysticercosis [3, 7].

Some reports show that sex hormones are involved in favoring cysticercosis in female pigs, revealing that the frequency of $T$. solium cysticercosis in pigs is increased during pregnancy, which is characterized by a significant elevation in progesterone levels $[8,9]$. As a consequence, the sex hormones might affect the course of $T$. solium parasite infection [10-14]. Furthermore, we have previously found that in vitro treatment with progesterone ( $\mathrm{P}_{4}$ hereinafter) increases evagination and growth of $T$. solium cysticerci [15], thus demonstrating a direct effect of $\mathrm{P}_{4} . \mathrm{P}_{4}$ effects could be mediated by the presence of a putative progesterone-binding protein in the parasite resembling either a nuclear classical progesterone receptor (PR), or a membrane receptor. In T. crassiceps, another related cestode, we have also demonstrated that $\mathrm{P}_{4}$ treatment increases parasite loads 2 -fold in females and 3 -fold in males, as compared to controls [16]. $\mathrm{P}_{4}$ is also able to stimulate in vitro reproduction of $T$. crassiceps cysticerci, suggesting the existence of a progesteronebinding protein in Taenia spp. [16]. Likewise, $\mathrm{P}_{4}$ treatment increases cytoskeleton protein expression including actin, tubulin and myosin in T. crassiceps, all prominent components of flame cells belonging to the parasite excretory system [17].

Progesterone can exert its actions through nongenomic mechanisms mediated by the interaction with progesterone-binding membrane proteins including progesterone membrane receptors (mPRs) and the progesterone membrane components (PGRMC-1 and PGRMC-2) [18]. These progesterone membrane components were described to be putative progesterone receptors HPR6.6 (PGRMC-1) and Dg6 (PGRMC-2) in humans [19].

PGRMC-2 is expressed in several tissues, particularly in the placenta and other tissues belonging to the reproductive system. However, it has been shown that PGRMC-2 can be also expressed in non-reproductive tissues such as liver and nervous tissue. Interestingly, PGRMC-2 has been found in other organisms. To this regard, Caenorhabditis elegans has been demonstrated to express Vem-1, an analogous protein to PGRMC-2 in mammals [20]. In the specific case of helminth parasites, there are a few studies reporting the presence of PGRMC receptors. In this regard, numerous sex hormone-receptor-related proteins, including PGRMC, small androgen receptor-interacting proteins, progesterone-receptor associated p48 protein and progestin-induced protein, have been found in $S$. japonicum EST data [21, 22]. Likewise, several nuclear receptors and thyroid-hormone-associated proteins were identified in S. mansoni EST data [21-23].

The study of this type of progesterone binding molecules might help to expand knowledge on Taenia spp. biology in terms of differentiation, reproduction and development, as well as generating possible pharmacological targets that could be used in antihelminth drug therapy.

The aim of the present study was to explore the hypothesis that direct effects of $\mathrm{P}_{4}$ on $T$. solium cysticerci are mediated through a novel steroid-binding parasite protein resembling to PGRMC, by means of in vitro cell cultures, immunofluorescence, flow cytometry, twodimension electrophoresis (2D-E), protein sequencing, molecular modeling, docking analysis and phylogenetical computational analysis.

\section{Methods \\ Parasites}

Taenia solium cysticerci were dissected from skeletal muscle of naturally infected pigs. The fibrous capsule that surrounds each parasite was carefully separated using a dissection microscope. Once dissected, cysticerci were placed in tubes containing sterile PBS $(1 \times)$ supplemented with $100 \mathrm{U} / \mathrm{ml}$ antibiotics-fungizone (Gibco, St Louis Missouri, USA). Samples were centrifuged at $800 \times g$ at $4{ }^{\circ} \mathrm{C}$ for $10 \mathrm{~min}$ and supernatants were discarded. Pellets containing cysticerci were incubated in Dulbecco's Modified Medium (DMEM) without fetal calf serum supplementation (Gibco). Collected parasites were centrifuged three times at $800 \times g$ 10 min and washed with DMEM after each centrifugation. After the final wash, viable parasites (complete and translucent cystic structures) were counted using a binocular microscope. Ten viable cysticerci were then collected and dispensed into single 6-well culture plates (Falcon, BD Labware,) using $5 \mathrm{ml}$ DMEM medium (Gibco) each and then incubated at $37^{\circ} \mathrm{C}$ in $5 \% \mathrm{CO}_{2}$. 
In vitro treatment effects of $\mathrm{P}_{4}$ on $T$. solium cysticerci Evaluation of $\mathrm{P}_{4}$ effects on $T$. solium cysticerci was conducted as previously reported by Escobedo et al. [15]. In brief, for in vitro tests, water-soluble $\mathrm{P}_{4}$ was obtained from Sigma (St Louis, Missouri) and dissolved in DMEM serum-free culture medium at a final stock concentration of $1 \mathrm{mg} / \mathrm{ml}$ and sterilized by filtration using a $0.2 \mathrm{~mm}$ Millipore filter. Parasites were cultured in the presence of pure cultured medium or culture medium supplemented with $0.3 \%$ ethanol as vehicle (control groups). Also, parasites were separately cultured with $40 \mathrm{nM}$ of $\mathrm{P}_{4}$. Cysticerci from all treatments were cultured for 5 days in $5 \mathrm{ml}$ DMEM-medium and incubated at $37{ }^{\circ} \mathrm{C}$ in $5 \% \mathrm{CO}_{2}$. We carried out daily inspections concerning the scolex evagination and worm length. $\mathrm{P}_{4}$ reagent was prepared at $100 \mu \mathrm{l}$ final volume and added to each well containing parasites. The culture media was replaced every $24 \mathrm{~h}$ for 5 days. Finally, scolex evagination and worm length were registered using an inverted microscope (Olympus, MO21, Tokyo, Japan). Worm length was considered as the millimetric sum of scolex, neck and strobila.

\section{Progesterone-binding protein location in $T$. solium cysticerci by immunofluorescence}

Cultured T. solium cysticerci were washed with PBS $1 \times$ and embedded in Tissue Tek (Triangle Biomedical Science, Arizona, USA), and immediately frozen at $-80{ }^{\circ} \mathrm{C}$ until use. Parasitic tissue sections $(5 \mu \mathrm{m})$ were fixed with frozen acetone for $10 \mathrm{~min}$, washed 3 times in PBSTween $0.3 \%$ and blocked for $1 \mathrm{~h}$ with PBS containing $1 \%$ bovine albumin. Cross-sections were then incubated with a 1:100 dilution of PGRMC polyclonal antibody obtained from $T$. spiralis PGRMC (cloned, sequenced, synthesized and produced by Dr. Romel HernándezBello, who kindly donated it to us) for $45 \mathrm{~min}$ at $37{ }^{\circ} \mathrm{C}$, washed with PBS and then incubated with Alexa 488conjugated rabbit anti-mouse antibody (Invitrogen, California, USA) at 1:300 dilution. Control experiments were assessed incubating the $5 \mu \mathrm{m}$ thick tissue sections in the presence of Alexa 488-conjugated rabbit antimouse antibody alone at the same dilution. To eliminate background fluorescence, samples were contrasted with 0.025\% Evans Blue for $10 \mathrm{~min}$. After two single washings, samples were mounted in Vectashield mounting medium (Vector Laboratories Inc.,Boston, USA) and examined with a Carl Zeiss epifluorescence microscope (Carl Zeiss, Berlin, Germany).

\section{Detection of the progesterone-binding protein in tegu- mental cells of $T$. solium cysticerci by flow cytometry}

Taenia solium cells were extracted by cysticerci tissue disruption with nylon mesh and syringe plunger from cultured treated and un-treated parasites as previously described [24]. In brief, we first disrupted the entire cisticerci by passing them though a $3 \mathrm{ml}$ syringe and then, the remaining "envelope" was macerated by using a nylon mesh "sandwich" (150 mm) and a syringe plunger. At each step we looked for cells at the microscope and found that this procedure was sufficient for having isolated parasite derived cells [24]. Cells were centrifuged at $1680 \times g$ for $10 \mathrm{~min}$, and they were resuspended in $100 \mu \mathrm{l}$ FACS buffer (phosphate-buffered saline (PBS) $\mathrm{pH} 7.4,2 \% \mathrm{SFB}, 0.02 \% \mathrm{NaN}_{2}$ ) and $100 \mu \mathrm{l}$ paraformaldehyde $4 \%$ in PBS $1 \times$ (PF4) was added to fix the cells for $10 \mathrm{~min}$ at $37{ }^{\circ} \mathrm{C}$. One millilitre of ice-cold $\mathrm{MetOH}$ was added immediately after and incubated for $30 \mathrm{~min}$ at $4{ }^{\circ} \mathrm{C}$. Cells were centrifuged at $2240 \times g$ for $10 \mathrm{~min}$, decanted and washed 3 times with FACS buffer. $30 \mu \mathrm{l}$ of goat anti-mouse PGRMC polyclonal antibody (donated by Dr. Romel Hernández-Bello) was added and incubated for $10 \mathrm{~min}$. Cells were washed with $1 \mathrm{ml}$ FACS buffer and centrifuged as described above. Finally, cells were incubated with $30 \mu \mathrm{l}$ of secondary antibody for $10 \mathrm{~min}$. Cells were washed twice, resuspended in $200 \mu \mathrm{l}$ FACS buffer and stored in dark conditions at $4{ }^{\circ} \mathrm{C}$. Stained cells were registered using a FACSCalibur flow cytometer (Beckton Dickinson, California, USA), and data were analyzed with Flow $\mathrm{Jo}^{\circledR}$ software.

\section{PGRMC-like protein sequencing by $2-D E$ and mass spectrometry}

Total protein from cultured T. solium cysticerci was extracted and quantified as described before. Protein samples were placed in a buffer containing $8 \mathrm{M}$ urea, $2 \%$ CHAPS, 50 mM DTT, IPG pH 3-10 (Bio-Rad, California, USA) and bromophenol blue. Immediately after, protein samples were incubated overnight with the firstdimension gel (Amersham, Amsterdam, Netherlands). Once they were accurately hydrated, the first-dimension gel was isoelectrofocused with a constant voltage on a lineal electric gradient. After this, gel was equilibrated in a buffer containing $6 \mathrm{M}$ urea, 2\% SDS, $375 \mathrm{mM}$ Tris pH 8.8, 2\% DTT and 20\% glycerol for 15 min. Next, the same equilibration process was performed using iodoacetamide $25 \mathrm{mg} / \mathrm{ml}$ instead of DTT. Once equilibrated, the gel was separated according to the molecular size of each protein in a second-dimension gel (PAGE-SDS al $12.5 \%)$. A single protein spot corresponding to the expected molecular weight and predicted isoelectrical point was cut-out and sequenced by MALDITOF-TOF mass-spectrometry.

\section{Modeling, docking and molecular dynamics of the putative progesterone receptor membrane component PGRMC}

Initial model generation was accomplished by using the hydrophilic segment of PGRMC sequence and submitting 
it to Rosetta Homology modeling [25]. The sequence used was: SARGKHSNHEKLPNMRKRDFTIQELSQFNGNGP DGRILIAVNGNVFDVTNNGKEFYGKDG PYAIFAGRDA SRSLTMFTTDIPPCIEEYDDLSDLTSDQMKSLKEWELQF RERYPLVGKLLSPSEPHHLYESADNEESSQIDALTGSAKP KTDXSNAIYDILCTHCSRPLSILSLFLDFPIVVESSSCAYF VSVCAPVYTSLIVLXVFCFNNAPXFID.

Resulting models clustered close together (RMSD 1.14 to 1.46); only the model ranked first exhibited a surface pocket that could permit a hydrophobic ligand to bind to PGRMC. Thus, after a round of energy minimization, we selected that model to perform ligand docking.

Blind docking was performed using Vina 1.1.2 [26] on a single node from the LNS (Laboratorio Nacional del Supercomputo del Sureste de México). All ligands were obtained from the ZINC database [27] and converted to PDBQT format using the GUI provided by Autodock Tools [28]. Ligands were checked manually against the known chemical structure and all their rotatable bonds were allowed to remain free from restrain during docking. The receptor, i.e. PGRMC, was kept rigid. Docking employed a grid of dimensions $40 \times 40 \times 40$ with a $1 \AA$ grid size. Exhaustiveness was always set to 5000. Analysis of the docking results was performed in PyMOL as well as Daniel Seelinger's Autodock/Vina plugin.

Molecular Dynamics were performed using AMBER14 [29] in a GPU powered supercomputer. The force field employed was amberff14SB, an all-atom force field, with SPC/E water molecules. The system was solvated in an octahedron and neutralized with sodium ions. Ligands charges were fitted using Gaussian03 and the rest of its parameters taken from GAFF [30]. Simulations were carried out at $300 \mathrm{~K}$; each system was prepared by energy minimizing the water box, then the protein with the water box. The temperature was slowly raised from $0{ }^{\circ} \mathrm{C}$ to $300{ }^{\circ} \mathrm{C}$ and then a $1 \mathrm{~atm}$ pressure applied on the system. The production runs of 100 ns were started after these steps from the docking results. To allow for the equilibration of the ligand in its binding site, only the last $50 \mathrm{~ns}$ were employed in further calculations. MMGBSA (Molecular Mechanics/Generalized Born Solvent Accesible [31]) calculations were performed within AMBER. Visualization was done using VMD [32] and figures were prepared with UCSF Chimera [33].

\section{Alignment and phylogenetic analysis}

The sequence obtained in the present work for progesterone receptor component of T. solium was aligned separately with other 21 sequences downloaded from the GenBank database, including 4 sequences for Platyhelminthes, 2 for nematodes, 3 for arthropods and 12 for vertebrates including mammals, birds, reptiles and fish. The alignment included 133 characters (amino acids) and was constructed using Clustal W [34] with default parameters and adjusted manually within Mesquite [35]. The genetic divergence among taxa was estimated using uncorrected "p-distance" with MEGA version 6 [36]. The tree was constructed with neighbor-joining method and the nodes of the tree were supported with 10,000 bootstrap replicates.

\section{Videomicroscopy of live evaginated $T$. solium cyscticerci}

Live cysticerci were maintained for five days in DMEM medium supplemented with $25 \mathrm{mM}$ HEPES buffer adjusted to $\mathrm{pH} 7.2$ and $30 \mathrm{mM}$ carbonate salts. Parasites were maintained in a humidified incubator at $37^{\circ} \mathrm{C}$ in a $5 \% \mathrm{CO}_{2}$ environment. Filming motion of live parasites was performed in a microscope (Olympus, MO21).

\section{Experimental design and statistical analysis}

The response variable used in statistical analyses was the number of evaginated scolices that showed growth and motility in all wells treated with $\mathrm{P}_{4}$, compared to untreated. Data of the four replicates of each treatment were expressed as the mean \pm standard deviation (SD). Data were analyzed using one-way analysis of variance (ANOVA) followed by a post-hoc Tukey's test. Differences were considered significant when $P<0.05$.

\section{Results}

\section{In vitro effects of $\mathrm{P}_{4}$ on $T$. solium cysticerci}

As previously reported, we confirm previous results that, when $T$. solium cysticerci were in vitro exposed to $P_{4}$, an increase in the scolex evagination was observed in all treated parasites as compared to control groups, where only $40 \%$ of them spontaneously evaginated (Fig. 1). Evaluation of viability in evaginated cysticerci was carried out daily to determinate worm motility in culture conditions. Clearly, progesterone-treated parasites look much better than control ones (Additional file 1: Movie 1). A close up of a $T$. solium cysticerci treated with progesterone, showed a complete differentiation of the scolex, with rostelum, ventosas, and proglottids. The $T$. solium worm is alive and moving, looking for anchorage to the host. Motility of evaginated cysticerci was constant through all days of in vitro culture, as previously reported (Additional file 2: Movie 2).

Detection of the putative progesterone binding protein in $T$. solium cysticerci by flow cytometry

In Fig. 2a, a dot plot showing the T. solium cell size and complexity is shown. In fact, parasite cells were approximately 3-fold smaller and exhibited less complexity than other cell types previously analyzed (Fig. 2a). We found T. solium cells expressing the PGRMC in basal conditions (Fig. 2b). Interestingly, the expression pattern of the PGRMC was not altered when parasites were stimulated with progesterone (Fig. 2c). 


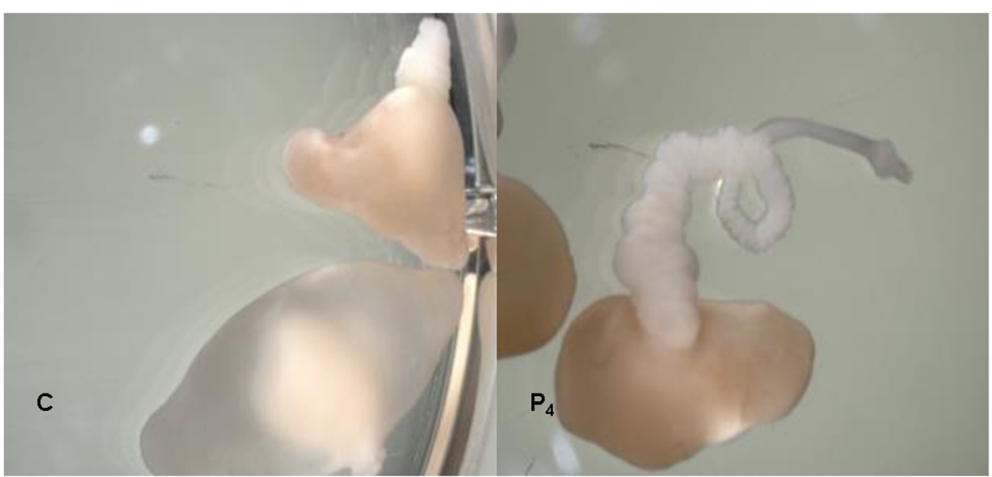

Fig. 1 Photographs of Taenia solium cysticerci in culture. Control cysticerci evaginated after 5 days in culture $(C)$ and cysticerci evaginated after 5 days in culture in the presence of $40 \mathrm{ng}$ of progesterone $\left(\mathrm{P}_{4}\right)$

Immunolocalization of a putative PR-binding protein in $T$. solium cysticerci

Immunofluorescence assays were performed to determinate the presence of the progesterone binding membrane protein in the $T$. solium cysticerci. Cysticerci incubated only in the presence of the isotype antibody and secondary antibody that were used as control, did not give any positive signal related to the progesterone binding membrane protein (Fig. 3a). Our result showed intense fluorescence detected in cysticercus subtegumental cells, revealing that progesterone-binding membrane protein is expressed in parasite cells (Fig. 3b). The

\section{a}

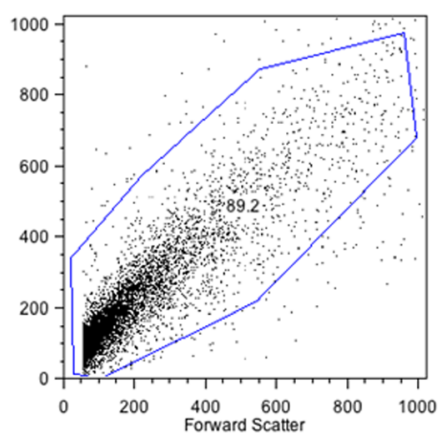

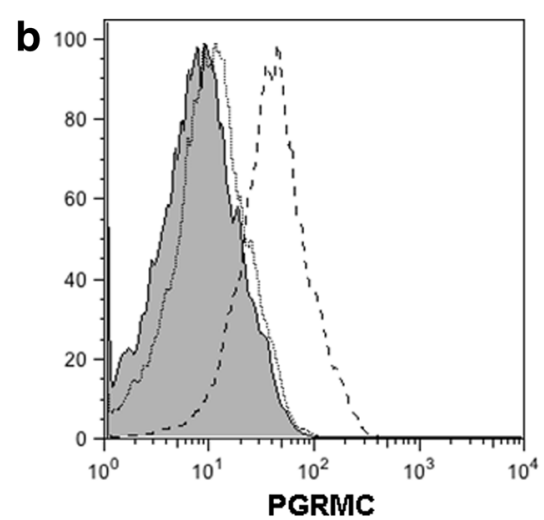

C 100

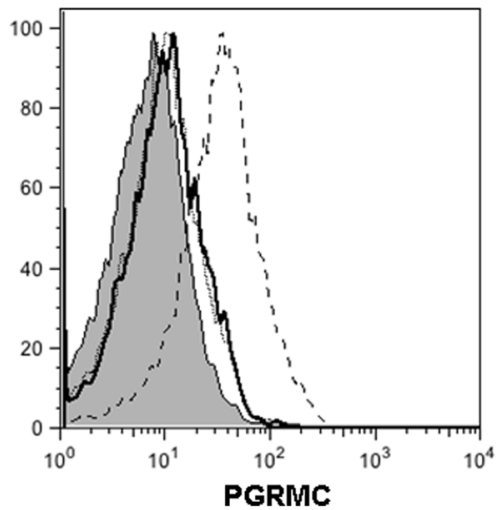

Fig. 2 Specific detection of the progesterone-binding protein in Taenia solium cysticerci by flow cytometry. FACS analysis in T. solium cysticercus cells showed the PGRMC expression. In untreated cysticerci used as controls, very few cells presented a low immuno-fluorescent signal, whereas $P_{4}$-treated cysticerci showed few cells with high immunofluorescent signal related to the receptor expressed in the parasite. a Size and complexity of T. solium cells. b PGRMC expression on T. solium cells. c PGRMC expression on T. solium cells after $\mathrm{P}_{4}$ stimulation. Solid lines show un-stained cells in all cases. Dotted lines correspond to unspecific staining of the secondary antibody and long-dashed lines correspond to the specific staining of PGRMC 

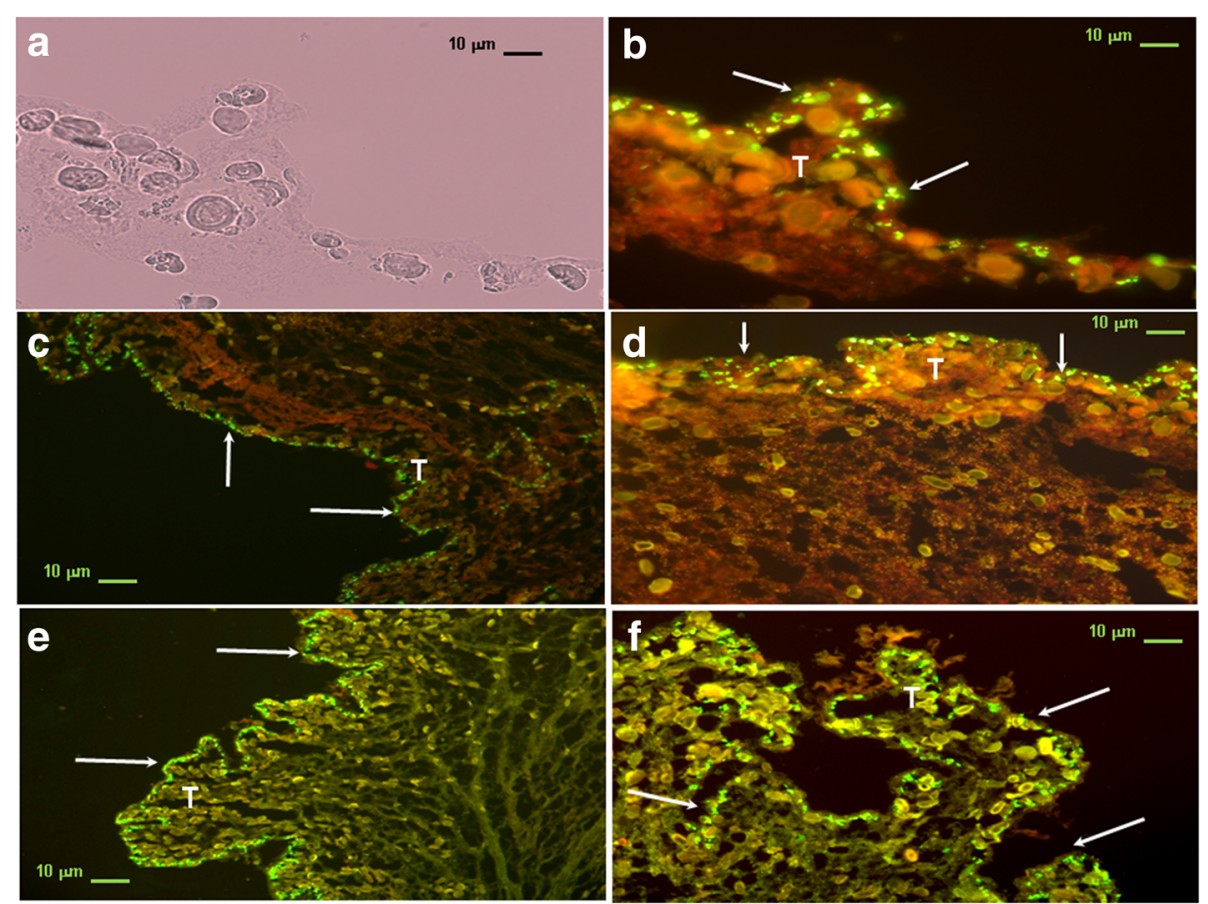

Fig. 3 Progesterone-binding membrane protein location in Taenia solium cysticerci by immunofluorescence. a Representative transversal sections of $T$. solium cysticerci where tegument, sub-tegument and cells are observed with optical microscopy illumination (Nomarski microscopy). b Negative control of immunofluorescence using the secondary antibody. c Specific detection of progesterone binding membrane protein in parasite (arrows) cells mainly located all along subtegumental tissue (magnification of 100x). $\mathbf{d}$ Detail of $\mathbf{c}$ showing T. solium cells expressing PGRMC exclusively on subtegument cells (arrows) at higher magnification (400x) from shows in. Abbreviations: T, tegumental cells; GL, germinal layer. Scale-bars: a, $10 \mu$ m; $\mathbf{b}$, $10 \mu \mathrm{m} ; \mathbf{c}, 10 \mu \mathrm{m} ; \mathbf{d}, 10 \mu \mathrm{m} ; \mathbf{e}, 10 \mu \mathrm{m} ; \mathbf{f}, 10 \mu \mathrm{m}$

distribution of the expression of the positive cells for PGRMC, is surrounding all the tegumental tissue (Fig. 3c). This finding confirmed that experimental conditions were optimal for detecting exclusively tegumental parasite cells expressing progesteronebinding membrane molecules and not false positive signals (Fig. 3d-f).

\section{D-E and localization of PGRMC}

Total proteins from $T$. solium cysticerci were separated in a $\mathrm{pH}$ range of 3-10, according to their isoelectrical point (IP) and molecular weight (Fig. 4a). Moreover, a well-defined protein spot around $\mathrm{pH} 5$ and $25 \mathrm{KDa}$ was recognized, corresponding to the IP of most of the sequenced PGRMC (Fig. 4a). Sequence of the corresponding protein spot of PGRMC is shown in Fig. 4b. Interestingly, this sequence showed high homology (90\%) to those sequences included in the T. spiralis genome (GenBank: EFV58821.1) [37]; S. japonicum genome (GenBank: CAX73419.1) [38]; S. haematobium genome (GenBank: KGB35529.1) [39]; and E. granulosus genome (GenBank: CDS20257.1) [40]; and 100\% homology to the sequence annotated in the $T$. solium genome (PRJNA170813, Worm Base Parasite) [40].

\section{Modeling PGRMC and docking to progesterone}

Homology modeling of the first 136 residues of PGRMC (sequence detailed in Methods) yielded a globular protein containing $19.1 \%$ alpha-helix, $14.7 \%$ beta-sheet and $25 \%$ without any predictive secondary structure (Fig. 5). This domain was found to be similar to a cytochrome b5, member of a family of steroid-binding proteins. Residues 137 to 217 were not modeled since no homology was found to any known protein and were excluded from docking analysis. Results from blind docking are shown in Table 1. Binding of steroids to our model is about $1 \mathrm{kcal} / \mathrm{mol}$ higher that to the control molecules, i.e. fatty acids. While steroids consistently found the same binding site (Fig. 5), fatty acids preferentially located either to an unstructured region of the model or to the same binding site as steroids. The binding site identified by docking contains a set of hydrophobic residues: F55, Y62, F77, W105 and T78 and R112 (numbering according to Methods). Since docking allows for the rotation of bonds within the ligand but not for the protein, we performed molecular dynamics simulations starting from the docking results for progesterone and stearic acid (Fig. 5a). The latter was selected as reference for MMGBSA, a method to estimate the relative binding 


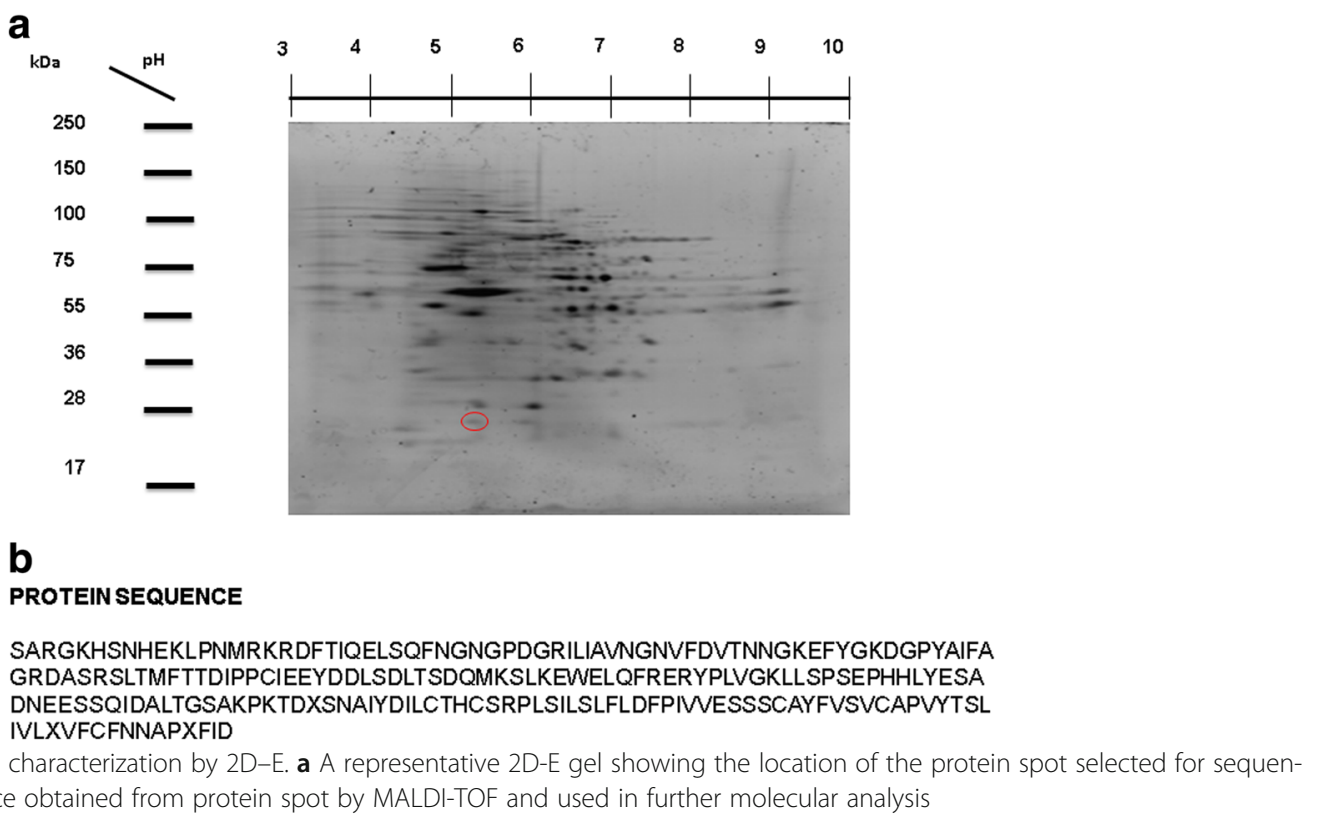
cing (red ellipse). b Sequence obtained from protein spot by MALDI-TOF and used in further molecular analysis

energies $\left(\Delta G_{\text {bind }}\right)$. Our simulations show that the binding site located by docking is indeed stable for $100 \mathrm{~ns}$ for both ligands, $\mathrm{P}_{4}$ and stearic acid. For the actual calculations, only the last $50 \mathrm{~ns}$ were used. $\Delta \mathrm{G}_{\text {bind }}$ for $\mathrm{P}_{4}$ and stearic acid were estimated as $-26.9 \pm 2.9$ and $-25.7 \pm 3.8$, respectively. Their $\Delta G_{\text {bind }}$ is -1.2 in line with the -1.4 obtained through docking. It is noteworthy that while their estimated binding energies are similar, the structure of our model experiences a conformational change in the presence of $\mathrm{P}_{4}$ but not stearic acid (Fig. 5a), suggesting a conformational change consistent with ligand-induced signaling by $\mathrm{P}_{4}$ but not stearic acid (Fig. 5).

\section{Phylogenetic analysis and sequence alignment}

The neighbor-joining tree obtained in the present study, brought to light that the progesterone receptor component of T. solium is related to a protein present in E. granulosus and both are nested within a cluster including

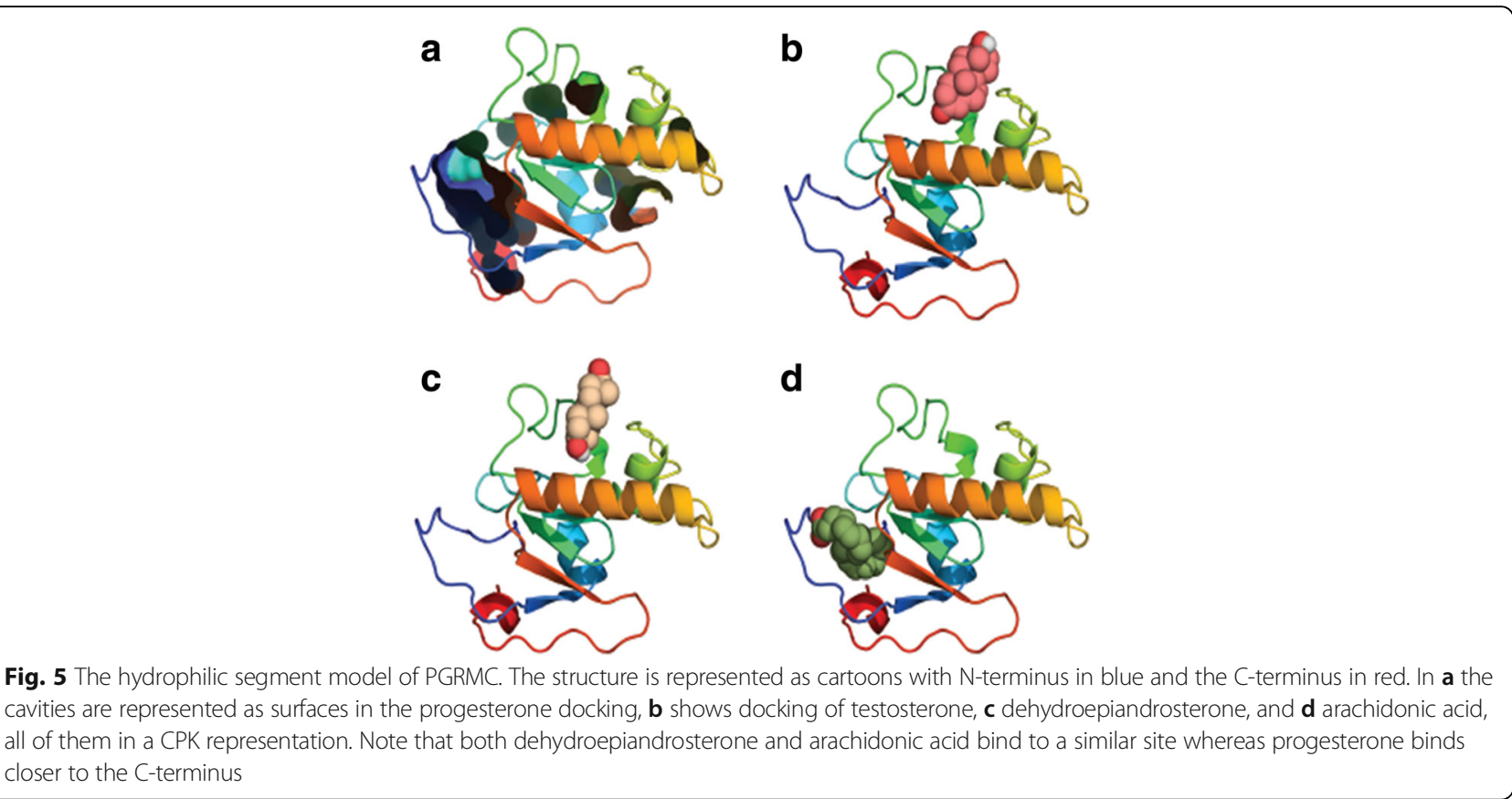


Table 1 Docking of several hydrophobic compounds to PGRC2. The data presented show the best result for each compound. Score is in $\mathrm{kcal} / \mathrm{mol}$, as calculated by Autodock Vina

\begin{tabular}{lll}
\hline Rank & Ligand & Score \\
\hline 1 & Dehydroepiandrosterone & -7.3 \\
2 & Testosterone & -7.2 \\
3 & 4-Dihydrotestosterone & -7.2 \\
4 & Estradiol & -7.1 \\
5 & Progesterone & -7 \\
6 & B-estradiol & -6.9 \\
7 & B-arachidonic & -5 \\
8 & Linoleic & -4.9 \\
9 & Oleic & -4.7 \\
10 & Palmitic & -4.4 \\
11 & Stearic & -4.3 \\
\hline
\end{tabular}

other Platyhelminthes such as Schistocephalus solidus and Schistosoma haematobium with a strong bootstrap support of $85 \%$. The neighbor-joining tree also placed together the two sequences of the progesterone receptor described for nematodes, whereas the three sequences for arthropods and the 12 sequences for vertebrates were spread out in different clusters (Fig. 6). Finally, sequences of the progesterone receptor component in the swine (Sus scrofa) and humans conformed a cluster in the tree with $100 \%$ bootstrap support. This cluster was very divergent to that progesterone receptor component found in $T$. solium (Fig. 6).

\section{Discussion}

As previously shown, the effects of $\mathrm{P}_{4}$ upon scolex evagination and adult worm growth were repeated and confirmed. To this regard, we demonstrated that the possible action mechanism through which $\mathrm{P}_{4}$ exerts its actions upon $T$. solium differentiation might involve the

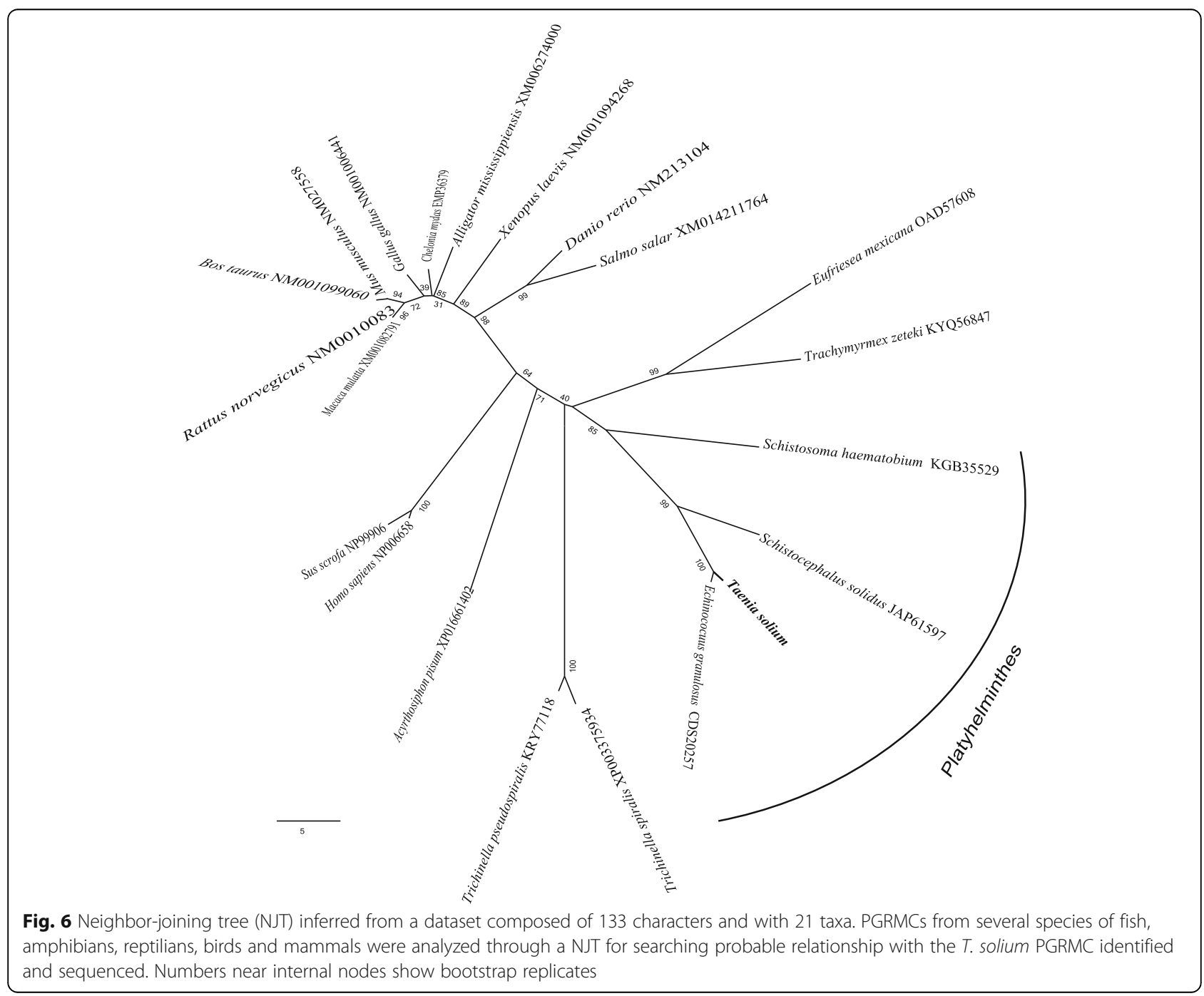


binding to a membrane protein as is the case of PGRMC. Our results show the presence of the progesterone binding membrane protein located at the cysticercus cell surface. This result suggests that helminths seem to have developed a molecule able to recognize progesterone (and possible other steroid hormones) with the aim of mediating its hormonal effects.

Interestingly, our results also suggest that the possible mechanism by which $\mathrm{P}_{4}$ exerts its actions upon cysticerci differentiation may primarily involve progesterone membrane receptors as well as nuclear PR-like proteins in a second plane. In order to examine the localization of the progesterone binding membrane protein in the T. solium cysticerci, immunofluorescence staining was performed. Interestingly, adjacent cells in the cysticerci tegument and subtegument showed intense fluorescent signal suggesting a mechanism where progesterone might be captured from the external environment. The idea is supported by the fact of having found PGRMC expression in cysticerci cells by flow cytometry. We found that T. solium-derived cells expressed some protein resembling the PGRMC. This finding may suggest that a putative steroid-binding protein present in the parasite might mediate $\mathrm{P}_{4}$ effect in the differentiation process of T. solium. Results also showed a slight increase in the amount of PGRMC on cysticercus cells treated with $\mathrm{P}_{4}$ as compared to cells derived from parasites cultured under control conditions. This finding suggests that $\mathrm{P}_{4}$ is able to increase the PGRMC expression, thus promoting scolex evagination.

Tsai et al. [40] sequenced the T. solium genome in 2013 by using the strategy of "shotgun genome sequencing". From these fragments, construction of genes present in the $T$. solium genome was carried out. These gene constructions opened the possibility of using hardware analysis to detect the presence of different coding sequences contained in the T. solium genome. These analyses were performed with bio-computer hardware like EAnnot, SNAP and FgenesH, which in turn are based on algorithms able to find preserved regions including exon-intron junction sites, and polyadenylated sequences. Notably, transcription of both exon-intron junction sites and polyadenylated sequences are partially regulated by the predicted form of the PGRMC [41]. As mentioned in the result section, this sequence $5^{\prime}$ and 3' seems to have lost the non-coding regions (UTR's) at the end as well polyadenylation sites [41].

In silico analysis regarding the predicted protein sequence of this transcript, gives place to an open reading frame corresponding to the whole sequence of RNA. The corresponding amino acid sequence was accurately translated using this sequence, by carrying out in silico analysis on the protein topology. Also, 2D-E coupled to mass-spectroscopy sequencing revealed the PGRMC sequence that was used to estimate its binding ability and possible evolutionary origin. As shown in Fig. 5, PGRMC has two domains corresponding to extra and intracellular compartments. This is consistent with previous works reporting PGRMC-1 and PGRMC-2 found in other species [41-43].

In parallel, using the BLAST platform to find conserve domains in this protein sequence, we determined that PGRMC has a binding domain to steroids in the Cterminal tail (118-to-168 aa sequence). To some extent, present finding disagrees with a previous study where authors claimed the binding domain to steroids is a transmembrane domain [44]. Interestingly, the freeliving nematode $C$. elegans presents DAF, which have a nuclear location, and different alleles of the gene that codifies for the receptor, and express those genes depending of the larvae stage of the nematode [20].

Furthermore, we determined that molecular weight of PGRMC in T. solium is $24.2 \mathrm{kDa}$, with isoelectric point around 4.9. In general, the known progesterone receptor membrane components range from 18 to $25 \mathrm{kDa}$. The $T$. solium PGRMC was detected in the parasite tegument that is the tissue in close contact to the host microenvironment. PGRMC-2 has been mainly detected on reproductive tissues of mammals, including ovary, endometrium, and placenta, where it has been associated with multiple cellular events such as maturation, differentiation and proliferation [42].

Escobedo et al. [15] demonstrated that progesterone, estradiol and testosterone have a direct effect on the $T$. solium cysticercus evagination. Specifically, progesterone increases evagination and parasite growth, whereas androgens induces parasite death [45]. Such different actions might be partially explained due to the fact that PGRMC appears to bind all these steroids with different affinity, which in turn is able to modify its cellular functions, as can be seen in Table 1 .

The neighbor-joining tree supported that PGRMC of $T$. solium is closely related to that of E. granulosus; both in turn are nested within a cluster, comprising other plathelminths such as S. solidus and S. haematobium. On the other hand, PGRMC sequences of the natural hosts (pigs and humans) were nested in a different cluster showing significant divergence with respect to T. solium.

\section{Conclusions}

A possibly functional PGRCM was found in T. solium and is described here. Whether the gene was acquired by $T$. solium through horizontal gene transfer or evolved by mimicry, or simply from common ancestral genes, remains to be elucidated. Our findings provide evidence on the crosstalk between host and parasite at molecular and evolutionary levels, providing new information which may be useful in designing anti-helminthic drugs, with the aim of specifically recognizing parasite cells with minimal secondary effects to the host. 


\section{Additional files}

Additional file 1: Movie 1. T. solium cysticerci control (right cyst) and treated with progesterone (left cyst). Progesterone treated one is evaginated and larger, and it is translucid and completely motile, looking for an anchor to a tissue. The control one, though evaginated, is smaller and it is opaque. (mov $10000 \mathrm{~kb}$ )

Additional file 2: Movie 2. Close up of a T. solium cysticerci treated with progesterone, in which the complete differentiation of the scolex, showing rostelum, ventosas, and proglottids is shown. The T. solium worm is alive and moving, looking for anchorage to the host. (mov $10300 \mathrm{~kb}$ )

\section{Acknowledgements}

The authors gratefully acknowledge the support of NVIDIA Corporation with the donation of the Tesla K20 GPU used for this research. The funders had no role in study design, data collection and analysis, decision to publish, or preparation of the manuscript.

\section{Funding}

Grant \# IN-208715 to JMM, was obtained from Programa de Apoyo a Proyectos de Investigación e Innovación Tecnológica (PAPIIT) from Dirección General de Asuntos del Personal Académico (DGAPA), Universidad Nacional Autónoma de México (U.N.A.M.), and Grant 176803 from Programa de Fondos Sectoriales CBSEP, Consejo Nacional de Ciencia y Tecnología (CONACyT) also to JMM. HA-D had a postdoctoral fellowship from the Programa de Becas Postdoctorales, DGAPA-UNAM

\section{Availability of data and materials}

The datasets used and/or analyzed during the current study are available from the corresponding author upon reasonable request.

\section{Authors' contributions}

HAD performed the isolation and culture experiments of the cysts in response to progesterone and drafting of the present paper. KENC made the "detection of the putative progesterone binding protein in T. solium cysticerci by flow cytometry" and drafting of the paper. GE made the "detection of the putative progesterone binding protein in T. solium cysticerci by immunofluorescence" and drafting of the paper. LDR made the "modeling of the PGRMC and the docking analysis to progesterone" and drafting of the paper. MGV made the phylogenetic analysis and sequence alignment. VHDA made the isolation of $T$. solium cysts from the pig tissues and participated in the cultures and drafting of the paper. MIPA performed the 2D experiments and isolation of the spot to sequencing and drafting of the paper. JMM participated in the design, analysis and writing of the paper. All authors read and approved the final manuscript.

\section{Ethics approval}

Animal care and experimentation practices at the School of Veterinary, UNAM, Cuautitlán, were evaluated and approved by the Institute's Animal Care and Use Committee, and by governmental agencies, in strict accordance with the recommendations set forth in the Guide for the Care and Use of Laboratory Animals of the National Institutes of Health of the USA, to ensure compliance with established international regulations and guidelines. Pigs were euthanized to obtain parasites by expert veterinary surgeons that used sodium pentobarbital anesthesia according to previously approved protocols in an effort to reduce animal suffering.

\section{Consent for publication}

Not applicable

\section{Competing interests}

The authors declare that they have no competing interests.

\section{Publisher's Note}

Springer Nature remains neutral with regard to jurisdictional claims in published maps and institutional affiliations.

\section{Author details}

'Centro Nacional de Investigación Disciplinaria en Parasitología Veterinaria, Instituto Nacional de Investigaciones Forestales Agrícolas y Pecuarias INIFAP, CP 62550 Jiutepec, Morelos, Mexico. ' Laboratorio de Genotoxicología y Medicina Ambientales. Departamento de.Ciencias Ambientales. Centro de Ciencias de la Atmósfera, Universidad Nacional Autónoma de México, 04510 Ciudad de Mexico, Mexico. ${ }^{3}$ Unidad de Medicina Experimental, Hospital General de México "Dr. Eduardo Liceaga", 06726 México DF, Mexico. ${ }^{4}$ Departamento de Ciencias Químico-Biológicas, Universidad de las Américas Puebla, Sta. Catarina Mártir, Cholula, C.P 72810 Puebla, Mexico. ${ }^{5}$ Instituto de Biología, Universidad Nacional Autónoma de México, CP 04510 Ciudad de Mexico, DF, Mexico. 'Departamento de Inmunología, Instituto de Investigaciones Biomédicas, Universidad Nacional Autónoma de México, AP 70228, 04510 Ciudad de Mexico, DF, Mexico.

Received: 2 October 2017 Accepted: 7 February 2018

Published online: 09 March 2018

\section{References}

1. Sciutto E, Cárdenas G, Adalid-Peralta L, Fragoso G, Larralde C, Fleury A Human neurocysticercosis: immunological features involved in the host's susceptibility to become infected and to develop disease. Microbes Infect. 2013;6(7):524-30.

2. Garcia HH, Del Brutto $\mathrm{OH}$. Neurocysticercosis: updated concepts about an old disease. Lancet Neurol. 2005;4(10):653-61.

3. Nash TE, Singh G, White AC, Rajshekhar V, Loeb JA, Proano JV, et al. Treatment of neurocysticercosis: current status and future research needs. Neurology. 2006;67(7):1120-7.

4. White AC Jr. Neurocysticercosis: a major cause of neurological disease worldwide. Clin Infect Dis. 1997;24(2):101-13.

5. Fan PC, Chung WC. Sociocultural factors and local customs related to taeniasis in east Asia. Kaohsiung J Med Sci. 1997;165:647-52.

6. Gonzalez AE, Gavidia C, Falcon N, Bernal T, Verastegui M, Garcia HH, et al. Protection of pigs with cysticercosis from further infections after treatment with oxfendazole. Amer J Trop Med Hyg. 2001;65(1):15-8.

7. Pawlowski Z, Allan J, Sarti E. Control of Taenia solium taeniasis/cysticercosis: from research towards implementation. Int J Parasitol. 2005:35(11-12):1221-32.

8. Bazer FW, Burghardt RC, Johnson GA, Spencer TE, Wu G. Interferons and progesterone for establishment and maintenance of pregnancy: interactions among novel cell signaling pathways. Reprod Biol. 2008;8(3):179-211.

9. Morales J, Velasco T, Tovar V, Fragoso G, Fleury A, Beltran C, et al. Castration and pregnancy of rural pigs significantly increase the prevalence of naturally acquired Taenia solium cysticercosis. Vet Parasitol. 2002;108(1):41-8.

10. Bottasso O, Morales-Montor J. Neuroimmunomodulation during infectious diseases: mechanisms, causes and consequences for the host. Neuroimmunomodulation. 2009:16(2):65-7.

11. Escobedo G, Lopez-Griego L, Morales-Montor J. Neuroimmunoendocrine modulation in the host by helminth parasites: a novel form of host-parasite coevolution? Neuroimmunomodulation. 2009;16(2):78-87.

12. Osorio Y, Bonilla DL, Peniche AG, Melby PC, Travi BL. Pregnancy enhances the innate immune response in experimental cutaneous leishmaniasis through hormone-modulated nitric oxide production. J Leukoc Biol. 2008; 83(6):1413-22

13. Santos CD, Toldo MP, Santello FH, Filipin Mdel V, Brazao V, do Prado Junior $J C$. Dehydroepiandrosterone increases resistance to experimental infection by Trypanosoma cruzi. Vet Parasitol. 2008;153(3-4):238-43.

14. Thabet HS, Thabet SS, Ali NM, Ahmed NS. Effects of ovariectomy and thyroidectomy on course and outcome of Trichinella spiralis infection in rat. J Egypt Soc Parasitol. 2008;38(1):29-46.

15. Escobedo G, Camacho-Arroyo I, Hernandez-Hernandez OT, Ostoa-Saloma P, Garcia-Varela M, Morales-Montor J. Progesterone induces scolex evagination of the human parasite Taenia solium: evolutionary implications to the hostparasite relationship. J Biomed Biotechnol. 2010;2010:591079.

16. Vargas-Villavicencio JA, Larralde C, Morales-Montor J. Gonadectomy and progesterone treatment induce protection in murine cysticercosis. Parasite Immunol. 2006:28(12):667-74.

17. Ambrosio JR, Ostoa-Saloma P, Palacios-Arreola MI, Ruiz-Rosado A, Sanchez-Orellana PL, Reynoso-Ducoing $\mathrm{O}$, et al. Oestradiol and progesterone differentially alter cytoskeletal protein expression and flame cell morphology in Taenia crassiceps. Int J Parasitol. 2014;44(10): 687-96. 
18. Kowalik MK, Rekawiecki R, Kotwica J. The putative roles of nuclear and membrane-bound progesterone receptors in the female reproductive tract. Reprod Biol. 2013;13(4):279-89.

19. Gerdes D, Wehling M, Leube B, Falkenstein E. Cloning and tissue expression of two putative steroid membrane receptors. Biol Chem. 1998:379(7):907-11.

20. Runko E, Kaprielian Z. Caenorhabditis elegans VEM-1, a novel membrane protein, regulates the guidance of ventral nerve cord-associated axons. J Neurosci. 2004;24(41):9015-26.

21. Hu W, Yan Q, Shen DK, Liu F, Zhu ZD, Song HD, et al. Evolutionary and biomedical implications of a Schistosoma japonicum complementary DNA resource. Nat Genet. 2003;35(2):139-47.

22. Oliveira G, Johnston DA. Mining the schistosome DNA sequence database. Trends Parasitol. 2001;17(10):501-3.

23. Verjovski-Almeida S, DeMarco R, Martins EA, Guimaraes PE, Ojopi EP, Paquola AC, et al. Transcriptome analysis of the acoelomate human parasite Schistosoma mansoni. Nat Genet. 2003;35(2):148-57.

24. Nava-Castro K, Hernandez-Bello R, Muniz-Hernandez S, Escobedo G, Morales-Montor J. New method to disaggregate and analyze single isolated helminthes cells using flow cytometry: proof of concept. J Biomed Biotechnol. 2011;2011:257060.

25. Raman S, Vernon R, Thompson J, Tyka M, Sadreyev R, Pei J, et al. Structure prediction for CASP8 with all-atom refinement using Rosetta. Proteins. 2009; 77(Suppl. 9):89-99.

26. Trott O, Olson AJ. AutoDock Vina: improving the speed and accuracy of docking with a new scoring function, efficient optimization, and multithreading. J Comput Chem. 2010;31(2):455-61.

27. Irwin JJ, Sterling T, Mysinger MM, Bolstad ES, Coleman RG. ZINC: a free too to discover chemistry for biology. J Chem Inf Model. 2012;52(7):1757-68

28. Morris GM, Huey R, Lindstrom W, Sanner MF, Belew RK, Goodsell DS, Olson AJ. AutoDock4 and AutoDockTools4: automated docking with selective receptor flexibility. J Comput Chem. 2009:30(16):2785-91.

29. Case DA, Darden TA, Cheatham TE III, Simmerling C, Wang J, Duke RE, et al. Amber 9, San Francisco: University of California; 2006.

30. Wang J, Wolf RM, Caldwell JW, Kollman PA, Case DA. Development and testing of a general Amber force field. J Comput Chem. 2004;25(9):1157-74.

31. Miller BR 3rd, TD MG Jr, Swails JM, Homeyer N, Gohlke H, Roitberg AE. MMPBSA.Py: an efficient program for end-state free energy calculations. J Chem Theory Comput. 2012;8(9):3314-21.

32. Humphrey W, Dalke A, Schulten K. VMD: visual molecular dynamics. J Mol Graph. 1996;14(1):33-8. 27-8

33. Pettersen EF, Goddard TD, Huang CC, Couch GS, Greenblatt DM, Meng EC, Ferrin TE. UCSF chimera - a visualization system for exploratory research and analysis. J Comput Chem. 2004;25(13):1605-12.

34. Thompson JD, Gibson TJ, Plewniak F, Jeanmougin F, Higgins DG. The CLUSTAL_X windows interface: flexible strategies for multiple sequence alignment aided by quality analysis tools. Nucleic Acids Res. 1997;25(24): 4876-82.

35. Maddison, W. P. and D.R. Maddison. 2018. Mesquite: a modular system for evolutionary analysis. Version $3.40 \mathrm{http}: / /$ mesquiteproject.org.

36. Tamura K, Stecher G, Peterson D, Filipski A, Kumar S. MEGA6: Molecular Evolutionary Genetics Analysis version 6.0. Mol Biol Evol. 2013;30(12):2725-9.

37. Mitreva M, Jasmer DP, Zarlenga DS, Wang Z, Abubucker S, Martin J, et al. The draft genome of the parasitic nematode Trichinella spiralis. Nat Genet. 2011:43:228-35.

38. Zhou Y, Zheng H, Chen X, Zhang L, Wang K, Guo J, et al. The Schistosoma japonicum genome reveals features of host-parasite interplay. Nature. 2009; 470(7253):345-51.

39. Young ND, Jex AR, Li B, Liu S, Yang L, Xiong Z, et al. Whole-genome sequence of Schistosoma haematobium. Nat Genet. 2012;44(2):221-5.

40. Tsai IJ, Zarowiecki M, Holroyd N, Garciarrubio A, Sanchez-Flores A, Brooks KL, et al. The genomes of four tapeworm species reveal adaptations to parasitism. Nature. 2013;496(7443):57-63.

41. Chen C, Sargent C, Quilter C, Yang Z, Ren J, Affara N, et al. Cloning, mapping and molecular characterization of porcine progesterone receptor membrane component 2 (PGRMC2) gene. Genet Mol Biol. 2010;33(3):471-4.

42. Cahill MA. Progesterone receptor membrane component 1: an integrative review. J Steroid Biochem Mol Biol. 2007:105(1-5):16-36.

43. Wendler A, Wehling M. PGRMC2, a yet uncharacterized protein with potential as tumor suppressor, migration inhibitor, and regulator of cytochrome P450 enzyme activity. Steroids. 2013;78(6):555-8.
44. Petersen SL, Intlekofer KA, Moura-Conlon PJ, Brewer DN, Del Pino Sans J, Lopez JA. Novel progesterone receptors: neural localization and possible functions. Front Neurosci. 2013;7:164.

45. Ambrosio JR, Valverde-Islas L, Nava-Castro KE, Palacios- Arreola Ml, OstoaSaloma P, Reynoso-Ducoing $\mathrm{O}$, et al. Androgens exert a cysticidal effect upon Taenia crassiceps by disrupting flame cell morphology and function. PLoS One. 2015;10(6):e0127928.

\section{Submit your next manuscript to BioMed Central and we will help you at every step:}

- We accept pre-submission inquiries

- Our selector tool helps you to find the most relevant journal

- We provide round the clock customer support

- Convenient online submission

- Thorough peer review

- Inclusion in PubMed and all major indexing services

- Maximum visibility for your research

Submit your manuscript at www.biomedcentral.com/submit 